DOE/ER/13836-6

\title{
AN INVESTIGATION OF CATALYTIC ACTIVE PHASE-SUPPORT INTERACTIONS BY IR, NMR AND X-RAY ABSORPTION SPECTROSCOPIES
}

\author{
Progress Report \\ for the period January 15, 1991 - July 31, 1993
}

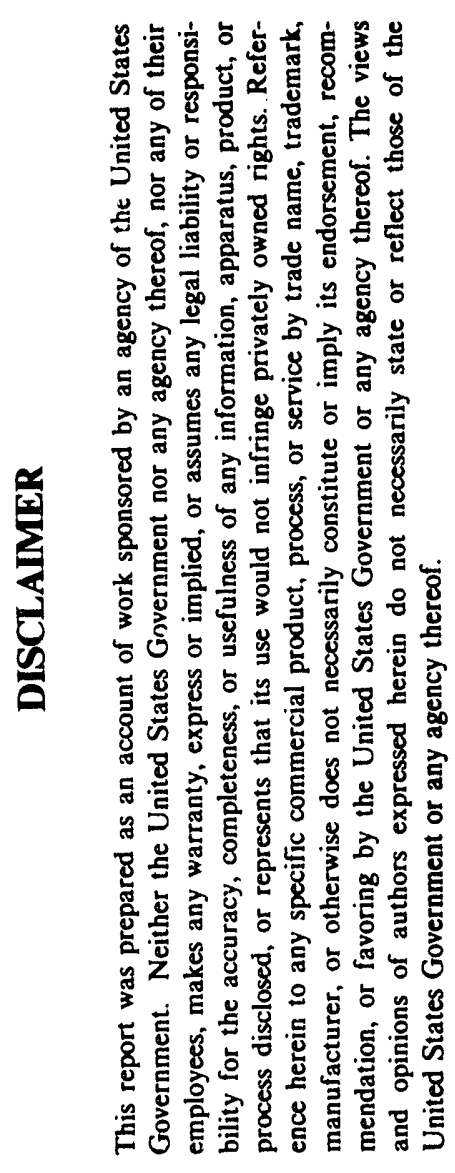

\author{
Gary L. Haller \\ Department of Chemical Engineering \\ Yale University \\ New Haven, CT 06520
}

July, 1993

Prepared for

THE U.S. DEPARTMENT OF ENERGY

AGREEMENT NO. DE-FG02-88ER13836

NOTICE

This report was prepared as an account of work sponsored by the United States Government. Neither the United States nor the Department of Energy, nor any of their employees, nor any of their contractors, subsontractors, or their employees, makes any warranty, express or implied, or assumes any legal liability or responsibility for the accuracy, completness, or usefulness of any information, apparatus, product or process disclosed or represents that its use would not infringe privately-owned rights. 
Active catalytic phases (metal, mixed metals, oxide or mixed oxides) interacting with oxide support on which the active phase is dispersed can affect the percentage exposed, the morphology of supported particles, the degree of reducibility of cations, etc., in a variety of ways. Our objective was to characterize the physical chemistry of the active phase-oxide support interaction by spectroscopic methods and to correlate this structure with catalytic function.

Solid state ${ }^{29} \mathrm{Si}$ NMR has been used to obtain a new correlation between the partial charge on the Si which comprises a part of the SiOHAl Brønsted acid structure in amorphous silica-aluminas. We also describe two potential improvements in solid state NMR applied to catalysts and catalysts supports. One of these is experimental, dynamic angle spinning NMR, a new technique for obtaining high resolution spectra of quadrupolar nuclei, e.g., ${ }^{27} \mathrm{Al}$. The second approach is an alternative to the standard fast Fourier transform of the free induction decay to convert from the time to spectral domain, the maximum entropy method.

The effect of different methods of preparation of Pd/L-zeolites is described. By comparison to analogous Pt systems, it is concluded that it is the inherent chemistry of the L-zeolite which results in better dispersion when impregnation preparation is used relative to ion exchange preparation.

$\mathrm{X}$-ray absorption spectroscopy is used to compare the effect of support $\left(\mathrm{SiO}_{2}\right.$ and $\mathrm{L}$-zeolite) on the degree and kind of Pt-Ni interaction. When supported in L-zeolite and promoted with $\mathrm{Ni}$, Pt has improved stability both with regard to self-poisoning and to sulfur catalyzed agglomeration.

\section{Introduction and Background}

The theme of our DOE sponsored rescarch over the last decade has been the investigation of the interaction of an active catalytic phase with an oxide support. Originally, we concentrated on group VIII metals, particularly $\mathrm{Rh}$, supported on reducible oxides such as $\mathrm{TiO}_{2}(1)$ and $\mathrm{V}_{2} \mathrm{O}_{3}$ (2). Much of this work has been summarized in an Advances in Catalysis review (3). More recently we have taken a broader view of active phase/support interactions and have studied an oxide interacting with the support to constitute a sitc, c.g., silica deposited on a $\gamma$-alumina support $(4,5)$, a metal interacting with a non-reducible support, c.g., $\mathrm{Pd} / \mathrm{L}$-zeolite (6), and metal-metal interaction modified by the support, e.g., Pt-Ni on $\mathrm{SiO}_{2}(7)$ and Lzeolite (8).

\section{Published Reports}

In the 30 months that this progress report covers, seven papers have appeared and two theses have been officially aceepted and published. All acknowledge DOE support. One of the papers and the theses, in part, are based on a previous DOE grant. The titles of these nine publications are listed below: 


\section{Articles}

"N-Butane Dehydrogenation and Isomerization Over Supported Platinum Catalysts: Comparison of SMSI on $\mathrm{TiO}_{2}$ and Sulfur Poisoning on $\mathrm{Al}_{2} \mathrm{O}_{3}$ Supports," J. Catal., 130, 359 (1991), with L. Bonneviot.

"Temperature Programmed Reduction of Silica Supported Pt/Ni Catalysts Studied by XANES", J. Phys. Chem., 96, 1324 (1992), with A. Jentys, B. J. McHugh and J. A. Lercher.

"Polymerization of Pyrrole over Pd and $\mathrm{SnO}_{2}$ Supported on KL-Zeolite, J. Phys. Chem., 96, 4145, (1992) with G. Larsen and M. Marquez.

"A XANES-TPR Study of Pt-Re/Al $\mathrm{O}_{3}$ Catalysts," J. Phys. Chem., 96, 9893 (1992), with F. Hilbrig and C. Michel.

"The Effect of Preparation Method on Metal-Support Interaction in Pd/L-zeolite Catalysts," Proc. 10th Intern. Congr. Catal., L. Guczi, F. Solymosi and P. Tétényi, eds., Elsevier Sci. Pub., Amsterdam, 1993, Part A, p. 297, with G. Larsen.

"Characterization of Pt-Ni/KL-Zeolite Bimetallic Catalysts by Chemisorption, Catalysis and X-ray Absorption," Proc. 9th Intern. Zeolite Conf., R. van Ballmoos, J. B. Higgins and M. M. J. Treacy, eds., Butterworth-Heinemann, Boston, 1993, vol. 2, p. 441, with G. Larsen.

"The Formation of Metallic Particles During Temperature Programmed Reduction of Silica Supported Pt and Ni Chlorides”, J. Phys. Chem., 97, 484 (1993), with A. Jentrys and J. A. Lercher.

\section{Theses}

"Characterization of Amorphous Silica-Alumina by Solid State NMR and Model Catalytic Reactions", C.

Y. Lin, Ph. D. Thesis, Yalc University, 1992.

"The Structural Investigation of Catalysts by a New Analysis of Their XAS and a More Appropriate Expression of Their EXAFS", B. J. McHugh, Ph. D. Yale University, May 1991.

\section{Progress Review}

A. Solid State NMR of Amorphous Silica-Alumina

\section{Acid Strength Correlation with Si Partial Charge}

The relationship between acidity of amorphous silica-aluminas and structure is a classic problem in heterogeneous catalysis and there have been developed several chemisorption techniques for quantifying 
acid strength (9). There have also been developed several catalytic reactions which provide a quantitative but relative measure of solid acidity. Among the latter is the recently reported reaction of 2-methyl-2pentene advanced by Kramer et al. (10). The isomerization of 2-methyl-2-pentene combines a double bond shift (which requires relatively low acid strength, i.c., occurs on essentially all acid sites) and a methyl shift (which requires relatively high acid strength). This reaction has several advantages as a probe for acidity. It involves a single reactant, the acidity strength correlates with selectivity (between the methyl and double bond isomerization) rather than rate, it spans a wide range of solid acidity and it correlates with the commercially important measure of cracking activity, the MAT number (11). Our goal was to extend the correlation of acidity measured by 2-methyl-2-pentene isomerization selectivity to a physical measure of the local surface structure as determined by ${ }^{29}$ Si MAS (Magic Angle Spinning) NMR.

A series of amorphous silica-aluminas of varying compositions (5-80 wt\% silica) were prepared by various methods which resulted in different local environments of the $\mathrm{Si}$. The structure around the average $\mathrm{Si}$ (ratio of Si/Al nearest neighbors, T-O-T bond angle where $\mathrm{T}$ is either $\mathrm{Si}$ or $\mathrm{Al}$, etc.) is reflected in the ${ }^{29} \mathrm{Si}$ NMR chemical shift which effectively measures the influence of this structure on the local electron density on the Si. The latter might be expected to correlate with the strength of acidity. The product selectivity (3-methyl-2-pentene/4-methyl-2-pentene) for 2-methyl-2-pentene isomerization increases monotonically as the mean ${ }^{29} \mathrm{Si}$ chemical shift moves up-field and passes through a maximum at about 80 $\mathrm{wt} \% \mathrm{SiO}_{2} / 20 \mathrm{wt} \% \mathrm{Al}_{2} \mathrm{O}_{3}$ and then the selectivity drops to zero at a chemical shift of pure $\mathrm{SiO}_{2}$. The methyl shift to double bond shift increases with catalyst acidity (10) and may be interpreted as acid site strength (methyl shift) normalized to acid site density (double bond shift) which correlates with the local electron density on $\mathrm{Si}$ and is more or less independent of the combination of factors (ratio of Si/Al nearest neighbors, T-O-T bond angle where $\mathrm{T}$ is either Si or $\mathrm{Al}$, etc.) that combine to perturb this local electron density.

By using the correlation between the calculated Si partial charge (total electron count less nuclear charge) and ${ }^{29} \mathrm{Si}$ chemical shift of several $\mathrm{Si}$ and $\mathrm{Si}-\mathrm{Al}$ small oligomers (dimers, trimers, etc.) of varying structure, c.g., linear or triangular trimer (12), we can re-plot our results and interpret the acidity in terms of the Si partial charge. Furthermore, we can say that the ${ }^{29} \mathrm{Si}$ chemical shift varies with both T-O-T bond angle and the Si/Al nearest neighbor ratio and thus so does that partial charge, i.e., it is the Si partial charge which is the fundamental parameter that determines the acidity of the bridging hydroxyl.

\section{NMR Development for Analysis of Catalysts and Catalyst Supports}

We have pursued two improvements in the applications of NMR to the characterization of catalysts. One of these is an experimental technique, i.c., dynamic angle spinning (DAS) NMR (13). This technique is a new approach for obtaining high resolution spectra of quadrupolar nuclei, c.g., $27 \mathrm{Al}$. (We have discussed DAS in some detail in a supplementary proposal which was funded and this will not be repeated here.) 
We have acquired a DAS probe and are learning how to use it. As a developmental alumina sample, we are using $\beta$ "-alumina $\left(\mathrm{Na}_{2} \mathrm{O}\right)_{\mathbf{X}}\left(11 \mathrm{Al}_{2} \mathrm{O}_{3}\right)$ where typically $1.15<\mathrm{X}<1.30$. This material is a solid electrolyte (which we are using in another project) and it has two convenient NMR nuclei $23 \mathrm{Na}$ and $27 \mathrm{Al}$ ). The former makes it reasonably easy to tune the DAS probe and practice our technique; the latter is the nucieus of ultimate interest in our study of amorphous silica-aluminas.

We have not completed our analysis of $\beta$ "-alumina from either the ${ }^{23} \mathrm{Na}$ or ${ }^{27} \mathrm{Al} \mathrm{NMR}$ point of view, but it is worth mentioning some the interesting preliminary observations. To convert the $\beta$ "-alumina into a proton conductor (our need in the other project), a portion or all of the $\mathrm{Na}$ is ion exchanged with $\mathrm{NH}_{4}{ }^{+}$. We observe two separate ${ }^{23} \mathrm{Na}$ NMR peaks in the origina! $\beta$ "-alumina, and onc of these disappears after $\mathrm{NH}_{4}{ }^{+}$exchange. We have also found that we can observe the ${ }^{14} \mathrm{~N}$ NMR spectrum. All of this is very encouraging both for the general development of characterization of aluminas and for the "specific characterization of the $\beta$ "-alumina.

Our second approach is calculational. As is the case in all Fourier spectroscopies, the fast Fourier transform (FFT) of the frec induction decay (FID) results in certain information loss when transforming from the time to spectral domain. Typically a filtering window (such as a simple exponential multiplication known as line broadening) is applied before spectral reconstruction to limit noise transmission into the spectrum, but this necessarily degrades resolution. A second common calculational problem is that the FID cannot be completely acquired, often because of a very long relaxation time of the NMR resonance. The FFT calculation then gives a spectrum with severe sidelobes (truncation noise). The Maximum Entropy (MEM) (14) and Linear Prediction (LPM) (15) methods of digital signal processing are newly develof $2 \mathrm{~d}$ (for NMR) techniques for spectral reconstruction and deconvolution which we are trying to apply to NMR of catalysts. MEM aims to avoid problems associated with the FFT calculation by attempting to select a spectrum whose inverse Fourier transform fits the FID to within the noise level (removes line broadening degradation of resolution). LPM discriminates between real signals and noise by applying the principle of linear prediction in the time domain and applying Lorentzian models to the lincar prediction solutions (removes truncation noise).

We conclude with an example of the MEM deconvolution of a commercial $45 \mathrm{wt} \% \mathrm{SiO}_{2}-55 \mathrm{w} / \%$ $\mathrm{Al}_{2} \mathrm{O}_{3}$ support. We have a series of these samples which all have the same nominal composition, but significantly different acidities and support propertics. In Table 1 below we show the analysis of silica and onc of the $45 \mathrm{w} 1 \% \mathrm{SiO}_{2}-55 \mathrm{w} 1 \% \mathrm{Al}_{2} \mathrm{O}_{3}$ supports.

The assignments of the three structural components of silica are from Sindorf and Maciel (16), and from the deconvoluted spectra, it is obvious that there exists a pure silica component of the mixed oxide. Given the relative amounts of the inter-bonding components, e.g., $\mathrm{Si}\left(\mathrm{Si}_{3} \mathrm{Al}\right)$ which implies tetrahedral bonding with three $\mathrm{Si}-\mathrm{O}$ - and one $\mathrm{Al}-\mathrm{O}$ - ligands, one can also deduce that there exists a separate alumina component by mass balance. However, with both the ${ }^{29} \mathrm{Si}$ and ${ }^{27} \mathrm{Al} \mathrm{NMR}$ spectra and resolution into the 
Table 1. MEM deconvolution of ${ }^{29} \mathrm{Si}$ NMR peaks into structural components (chemical shift in ppm relative TMS and intensity relative to largest component).

\begin{tabular}{|c|c|c|c|c|c|c|c|}
\hline Sample & $\mathrm{Si}(\mathrm{OSi})_{4}$ & $\mathrm{Si}(\mathrm{OSi})_{3} \mathrm{OH}$ & $\mathrm{Si}(\mathrm{OSi})_{2}(\mathrm{OH})_{2}$ & $\mathrm{Si}\left(\mathrm{Si}_{3} \mathrm{Al}\right)$ & $\mathrm{Si}\left(\mathrm{Si}_{2} \mathrm{Al}_{2}\right)$ & $\mathrm{Si}\left(\mathrm{SiAl}_{3}\right)$ & $\mathrm{Si}\left(\mathrm{Al}_{4}\right)$ \\
\hline \multicolumn{8}{|l|}{$\mathrm{SiO}_{2}$} \\
\hline ppm & -108 & -104 & -94 & & & & \\
\hline intensity & 100 & 9.2 & 1.7 & & & & \\
\hline \multicolumn{8}{|l|}{$\mathrm{SiO}_{2} \mathrm{Al}_{2} \mathrm{O}_{3}$} \\
\hline $\mathrm{ppm}$ & -108 & -104 & -94 & -98 & -90 & -86 & -82 \\
\hline intensity & 100 & 4.2 & 3.0 & 17.6 & 17.3 & 5.2 & 5.8 \\
\hline
\end{tabular}

inter-bonded components (from the ${ }^{29} \mathrm{Si} \mathrm{NMR}$ ) and the tetrahedral/octahedral alumina sites (from ${ }^{27} \mathrm{Al}$ NMR) and (wo-dimensional proton-Al and proton-Si spectra, we believe we will have a powerful analysis tool for these complex oxide mixtures.

\section{B. Effect of preparation Method on Pd/L-Zeolite Catalysts}

The discovery that $\mathrm{Pt} / \mathrm{L}$-zeolite is a non-acidic reforming catalyst that has high selectivity for the conversion of $n$-hexane to benzene has stimulated much interest in this catalyst (17). There is evidence of both geometric (channeling of reactant) (18) and electronic effects (19) on reactions in $\mathrm{Pt} / \mathrm{L}$-zeolite. The latter is most evident in the relative adsorption equilibrium constants extracted from competitive hydrogenation of benzene and toluene, a sensitive chemical probe of the electronic structure of the metal (20). These results suggest that L-zeolite acts as a base toward Pt particles. The degrec of interaction also appears to be a function of the preparation method such that impregnation to incipient wetness results in a higher dispersion than ion exchange.

The density of states at the Fermi level is about four times greater for Pd than for Pt (21) and correlates with the adsorption equilibrium constants extracted from competitive hydrogenation of benzene and toluene (20). This suggested that Pd will interact less strongly with L-zeolite channel walls than does $\mathrm{Pt}$. The objective of this study was both to confirm this hypothesis and to investigate the effect of preparation method on the dispersion/interaction to ascertain whether the higher dispersion of the impregnation preparation is a property of the L-zeolite more-or-less independent of the metal.

The catalysts were prepared by impregnation to incipient wetness or ion exchange using $\mathrm{Pd}\left(\mathrm{NH}_{3}\right)_{4}\left(\mathrm{NO}_{3}\right)_{2}$ precursor and $\mathrm{KL}$-zeolite to produce approximately $1 \mathrm{wt} \% \mathrm{Pd}$. The catalysts were calcined at $623 \mathrm{~K}$ in air and initially reduced at $493 \mathrm{~K}$. To remove acidity introduced by the reduction of the ion exchange preparation, the product was back exchanged by $\mathrm{K}^{+}$(or $\mathrm{Mg}^{2+}, \mathrm{Ca}^{2+}$ or $\mathrm{Ba}^{2+}$ ). For the impregnation preparation, calalysts were also back exchanged with $\mathrm{Mg}^{2+}, \mathrm{Ca}^{2+}$ or $\mathrm{Ba}^{2+}$. The ratio of toluene to benzene adsorption constants at $323 \mathrm{~K}$ were measured by competitive toluene/benzene hydrogenation as described in rel. (19). The average particle size was determined from the EXAFS 
coordination number in a manner similar to that described for $\mathrm{Pt}(22)$. The relative stability of the resulting catalyst dispersion was determined by sintering in one atm of $\mathrm{H}_{2}$ at different temperatures and measurement of the change in dispersion by $\mathrm{O}_{2}$ titration of adsorbed $\mathrm{H}_{2}$ (23).

The average coordination number of Pd particles measured by EXAFS is 5.6 and 7.3 for Pd/KLzcolite prepared by impregnation and ion exchange, respectively, a result in qualitative agreement with what has been observed for $\mathrm{Pt} / \mathrm{KL}$--zeolite. This indicates that the higher dispersion of the impregnation preparation is an inherent property of L-zeolite/preparation method and not dependent on the metal.

The ratio of adsorption equilibrium constants, $\mathrm{K}_{\mathrm{t} \text { olucne }} / \mathrm{K}_{\text {benzene }}=\mathrm{K}_{\mathrm{l} / \mathrm{b}}$, is expected to be smaller for Pd than for Pt (because of the higher density of states on Pd) and to decrease with donation of charge from the support to the metal. $\mathrm{K} / / b$ (at $353 \mathrm{~K}$ on $\mathrm{Pt} ; 323 \mathrm{~K}$ on $\mathrm{Pd}$ ) is 5.8 and 2.0 on $\mathrm{Pt} / \mathrm{SiO}_{2}$ and $\mathrm{Pd} / \mathrm{SiO}_{2}$, respectively, and 5.0 and 1.6, on $\mathrm{Pt} / \mathrm{KL}$-and $\mathrm{Pd} / \mathrm{KL}$-zeolite, respectively, both prepared by ion exchange. Thus, the ordering of the metals, $\mathrm{Pt}>\mathrm{Pd}$, and of the supports, $\mathrm{SiO}_{2}>\mathrm{KL}$-zeolite, is as expected and there is an indication that the L-zeolite interacts with both Pt and Pd as a base, i.e., appears to transfer charge to the metal.

While the interaction between L-zeolite and either Pt or Pd is qualitatively similar, the high density of states of Pd causes the interaction to be weaker. This is reflected in the stability with respect to sintering in $\mathrm{H}_{2}$. Between 493 and $753 \mathrm{~K}$, the temperature of reduction has a small effect on dispersion in $\mathrm{Pt} / \mathrm{L}$ zcolite (24). However, $\mathrm{Pd} / \mathrm{L}$-zeolite is very unstable to even modest thermal treatments in $\mathrm{H}_{2}$. The dispersion decreases to about one fourth of that after the initial $493 \mathrm{~K}$ reduction following reduction at $753 \mathrm{~K}$. Further evidence that this is the result of the high density of states on Pd is indicated by the fact that the relative loss of dispersion by Pd/KHL-zeolite (the protons resulting from the reduction of the ion exchange preparation) is slower than $\mathrm{Pd} / \mathrm{KL}$-zeolite (impregnation preparation) at $553 \mathrm{~K}$.

\section{Characterization of Pt-Ni/KL-Zcolite Bimctallic Catalysts \\ 1. Chemical Characterization}

It is of interest to understand the nature of metal-metal interaction and its affects on catalysis. Recently, significant progress has been made by the investigation of model systems using surface science techniques (25). However, it is of practical interest to understand these effects on small particles where the support may influence the metal-metal interaction. We have selected L-zeolite as a support with the goal of constraining the particle size and making the distribution narrow by preparation of the particles in the zeolite channels. Preliminary work on co-ion exchanged and sequential ion exchanged (Pt ion exchange and reduction followed by $\mathrm{Ni}$ ion exchange and reduction were less successful in this regard relative to the co-impregnation.) We summarize here the characterization of a Pt-Ni/KL-zeolite series and compare it to the unsupported model system of Ni layers (sub-monolayer to 3 layers) on a Pt (111) single crystal (26). The preparation of these catalysts and other experimental details are described in ref (8). 
Table 2 presents the $\mathrm{H} / \mathrm{M}$ ratios, wt $\%$ metal loading and atomic fraction of $\mathrm{Pt}, \mathrm{X}_{\mathrm{Pl}}$. A summary of the cyclopropane hydrogenolysis kinetic data is given in Table 3. There are two parallel reactions, ring opening (RO) to form propane and double cracking (DC) to form methane and ethane.

Table 2. Catalyst composition.

\begin{tabular}{|l|c|c|c|c|}
\hline Catalyst & $\mathrm{H} / \mathrm{M}$ & $w \mathrm{w} \% \mathrm{Pt}$ & $\mathrm{X}$ & $\mathrm{X}$ \\
& & & & \\
$\mathrm{Pl} / \mathrm{KL}$ & 0.58 & 5.31 & - & 1.00 \\
\hline $0.70 \mathrm{Pt}-\mathrm{Ni} / \mathrm{KL}$ & 0.50 & 5.43 & 0.71 & 0.70 \\
$0.53 \mathrm{Pt}-\mathrm{Ni} / \mathrm{KL}$ & 0.45 & 5.02 & 1.33 & 0.53 \\
$0.44 \mathrm{Pt}-\mathrm{Ni} / \mathrm{KL}$ & 0.39 & 5.12 & 1.93 & 0.44 \\
\hline
\end{tabular}

Table 3. Activation energies, orders of reaction, selectivity and turnover frequency for ring opening (RO) of cyclopropane.

\begin{tabular}{|c|c|c|c|c|c|}
\hline Catalysı & $\begin{array}{c}\text { app.E } E_{a} \\
\mathrm{Kcal} / \mathrm{mol}\end{array}$ & $\mathrm{n}$ for $\mathrm{H}_{2}^{\mathrm{a}}$ & $m$ for $\mathrm{cC}_{3} \mathrm{H}_{6}{ }^{\mathrm{a}}$ & $S^{b}$ & $\begin{array}{r}\mathrm{TOF} \\
\times 10^{3} \\
\hdashline 10^{3}\end{array}$ \\
\hline $\mathrm{Pl} / \mathrm{KL}$ & 17.1 & -0.24 & 1.25 & 1.00 & 2.4 \\
\hline $0.70 \mathrm{Pl}-\mathrm{Ni} / \mathrm{KL}$ & 14.4 & -0.26 & 1.00 & 0.80 & 21.1 \\
\hline $0.53 \mathrm{Pl}-\mathrm{Ni} / \mathrm{KL}$ & 14.3 & -0.17 & 0.86 & 0.82 & 26.3 \\
\hline $0.44 \mathrm{Pl}-\mathrm{Ni} / \mathrm{KL}$ & 13.4 & -0.22 & 0.86 & 0.80 & 34.8 \\
\hline
\end{tabular}

assuming a power rate law for ring opening, $\mathrm{r}_{\mathrm{RO}}=\mathrm{k}\left[\mathrm{H}_{2}\right]^{\mathrm{n}}\left[\mathrm{cC}_{3} \mathrm{H}_{6}\right]^{\mathrm{m}}$

bS $i_{\text {. }}$ electivity for ring opening defined as the ratio of moles converted to propane to total conversion of cych.spropane.

c Measured at $353 \mathrm{~K} . \mathrm{P}_{\mathrm{H}_{2}}=16.9 \mathrm{kPa}, \mathrm{P}_{\mathrm{cC}_{3} \mathrm{C}_{6}}=3.4 \mathrm{kPa}$. The cthanc/methane molar ratio was $(0.88$, (0.86, and 0.85 for the $0.70,0.53$ and $0.44 \mathrm{Pt}-\mathrm{Ni} / \mathrm{KL}$ catalysts, respectively.

Cyclopropane reaction is a structure insensitive (27), and because Ni is so much more active than Pt for the reactions of cyclopropane, it is mostly a probe for $\mathrm{Ni}$ in the bimetallic catalysts. The fact that all of the bimetallic catalysts are about a factor of 10 more active than the pure $\mathrm{Pt}$ and have cisentially a constant activation energy, activity and selectivity for conversion to methane + ethanc independent of $\mathrm{X}_{\mathrm{Ni}}$ is consistent with the Pt particles being covered with a surface layer of $\mathrm{Ni}$ of one or more layers in all catalysts.

One of our objectives, in the case of the L-zeolite supported catalysts, is to test the stability of the Pt versus the Pt-Ni with regard to deactivation and selectivity. It has been reported by Iglesia and Batumgartner $(28,29)$ that what makes Pt/L-zeolite unique is its stability against deactivation by coking. It is certainly superior to Pl on other supports, but there is still deactivation leaving room for further improvement. 
A selection of results for n-hexane conversion to benzene is presented below in Table 4. At low conversion there does not seem to be much effect of the Ni. At the lowest $\mathrm{Pt} / \mathrm{Ni}$ ratio the turnover frequency is only about half that for pure $\mathrm{Pt}$ and both the sclectivity and stability (based on the degree of deactivation between 15 and 135 minutes) have diminished slightly. However, at high conversion, the story is quite different. The selectivity does decrease some (from 0.88 to 0.82 ) but the stability it substantially improved increasing more than $40 \%$. This is a very important finding. It is likely that the stabilization may be even more significant at the high pressure conditions used in commercial practice.

Table 4. Conversion and selectivity on $n$-hexanc reaction at $\mathrm{T}=753 \mathrm{~K}, \mathrm{P}_{\mathrm{H}_{2}}=33.8 \mathrm{kPa}, \mathrm{P}_{\mathrm{n}-\mathrm{C}_{6}}=4.2 \mathrm{kPa}$ after 75 min on stream.

\begin{tabular}{|c|c|c|c|c|c|c|c|}
\hline Catalyst & \%Conv. & $\mathrm{C}_{1}$ & $\mathrm{C}_{2}-\mathrm{C}_{5}$ & $\mathrm{C}_{6}=$ & $\mathrm{Bz}$ & $\mathrm{S}_{\mathrm{Bz}}$ & $\mathrm{R}^{\mathrm{a}}$ \\
\hline \multicolumn{8}{|c|}{ Low Conversion } \\
\hline $\mathrm{Pt}$ & $10.3^{b}$ & 0.6 & - & 4.4 & 5.3 & 0.51 & 52 \\
\hline $0.70 \mathrm{Pt}-\mathrm{Ni}$ & $8.1^{b}$ & 0.5 & - & 2.9 & 4.7 & 0.58 & 45 \\
\hline $0.53 \mathrm{Pl}-\mathrm{Ni}$ & $6.3^{b}$ & 0.4 & - & 2.8 & 3.1 & 0.49 & 44 \\
\hline $0.44 \mathrm{Pl}-\mathrm{Ni}$ & $5.4^{\mathrm{b}}$ & 0.4 & - & 2.4 & 2.6 & 0.48 & 4.3 \\
\hline \multicolumn{8}{|c|}{ High Conversion } \\
\hline $\mathrm{Pt}$ & 39.6 & 4.8 & - & - & 34.8 & 0.88 & 36 \\
\hline $0.70 \mathrm{Pl}-\mathrm{Ni}$ & 39.8 & 5.3 & 0.3 & 0.1 & 34.1 & 0.86 & 42 \\
\hline ().53Pl-Ni & 54.4 & 7.5 & 0.4 & - & 46.5 & 0.85 & 50 \\
\hline $0.44 \mathrm{Pl}-\mathrm{Ni}$ & 50.1 & 9.0 & 1.0 & - & 46.1 & 0.82 & 52 \\
\hline
\end{tabular}

${ }^{a} \mathrm{R}$ is the relative activily measured as the conversion after 135 minutes on stream relative to 15 minutes on stream.

bTreating this as a differential conversion, the turnover frequencies are estimated to be $0.14,0.14,0.11$ and $0.063 \mathrm{~s}^{-1}$, respectively, at the conditions given.

\section{X-Ray Absorption Characterization of Pt-Ni Bimetallic Clusters on $\mathrm{SiO}_{2}$ and $\mathrm{L}$-Zeolite}

We have performed a comparative $X$-ray absorption investigation of $\mathrm{Pt}-\mathrm{Ni}$ on $\mathrm{SiO}_{2}$ (7) and $\mathrm{L}$ zeolite (8). In both cases the catalysts were prepared by co-impregnation to incipient wetness. On the $\mathrm{SiO}_{2}$ support, $\mathrm{PlCl}_{4}$ and $\mathrm{NiCl}_{2} \cdot 6 \mathrm{H}_{2} \mathrm{O}$ were the precursors while in the case of $\mathrm{L}-2 \mathrm{ze}$ lite $\mathrm{P}\left(\mathrm{NH}_{3}\right)_{4}\left(\mathrm{NO}_{3}\right)_{2}$ and $\mathrm{Ni}\left(\mathrm{NO}_{3}\right)_{3}$ were used. A selection of our EXAFS results are shown in Table 5 below. 
Table 5. Modeled EXAFS coordination number $\mathrm{N}_{X-Y}$ and interatomic distance $R_{X-Y}$ (where $X$ is the absorber and $Y$ the scatterer).

\begin{tabular}{|c|c|c|c|c|c|c|c|c|}
\hline Catalyst & $N_{P^{t}-P^{\prime} t}$ & $N_{P l-N i}$ & $\mathrm{~N}_{\mathrm{Ni}-\mathrm{Ni}}$ & $\mathrm{N}_{\mathrm{Ni}-\mathrm{Pl}}$ & $\mathrm{R}_{\mathrm{P} t-\mathrm{Pt}}$ & $\mathrm{R}_{\mathrm{Pt}-\mathrm{Ni}}$ & $\mathrm{R}_{\mathrm{Ni}-\mathrm{Ni}}$ & $\mathrm{R}_{\mathrm{Ni}-\mathrm{Pt}}$ \\
\hline $\mathrm{Pt} / \mathrm{SiO}_{2}$ & 10.6 & - & - & - & 2.77 & - & - & - \\
\hline $\mathrm{Pl} / \mathrm{KL}$ & 7.1 & - & - & - & 2.77 & - & - & - \\
\hline $0.70 \mathrm{Pt}-\mathrm{Ni} / \mathrm{SiO}_{2}$ & 6.3 & 4.2 & 4.4 & 8.6 & 2.76 & 2.70 & 2.60 & 2.70 \\
\hline $0.70 \mathrm{Pt}-\mathrm{Ni} / \mathrm{KL}$ & 6.7 & 0.6 & 2.3 & 4.9 & 2.75 & 2.69 & 2.58 & 2.69 \\
\hline $0.50 \mathrm{Pt}-\mathrm{Ni} / \mathrm{SiO}_{2}$ & 3.8 & 8.1 & 4.1 & 8.3 & 2.73 & 2.71 & 2.59 & 2.71 \\
\hline $0.53 \mathrm{Pt}-\mathrm{Ni} / \mathrm{KL}$ & 4.1 & 1.1 & 2.9 & 3.7 & 2.73 & 2.68 & 2.57 & 2.68 \\
\hline
\end{tabular}

It can be seen immediately that there are several differences between the two supports. Generally, the dispersions are poor on the $\mathrm{SiO}_{2}\left(22 \%\right.$ by $\mathrm{H}_{2}$ chemisorption on the $\mathrm{Pt} / \mathrm{SiO}_{2}$ sample compared to $58 \%$ on $\mathrm{Pt} / \mathrm{KL}$ ). However, of more interest is the effect of Ni on the apparent dispersion measured by EXAFS. We can take $\mathrm{NPt}_{\mathrm{Pt}}+\mathrm{N}_{\mathrm{Pt}-\mathrm{Ni}}$ as a measure of this effect. The total Pt coordination number for Pt rich samples, e.g., the 70 at\% Pt samples, are identical to pure Pt on both silica and L-zeolite (with in the uncertainty). However, for the 50 at $\% \mathrm{Pt}$ and Ni rich samples, the total coordination number increases on silica $(10.6<11.9)$ and decreases for $\mathrm{L}$-zeolite $(7.1>5.2)$ relative to pure Pt. Thus, on both silica and $\mathrm{L}$ zeolite the dispersion does not seem to be much affected when $\mathrm{Pt}$ is the major component, but as the composition approaches 50/50, the dispersion on silica appears to decrease while in L-zeolite it appears to increase. On both supports, the $\mathrm{R}_{\mathrm{Ni}-\mathrm{Ni}}$ is greater than for bulk $\mathrm{Ni}(2.492 \AA)$ and about equal to the bulk $\mathrm{PINi}$ alloy. The large $\mathrm{R}_{\mathrm{Ni}-\mathrm{Ni}}$ for Pt-Ni clusters on both silica and L-zeolite supports suggests metal-metal interaction in both cases. However, in the case of the 50 at\% $\mathrm{Pl}$ on silica, coordination numbers are essentially what would be expected for the bulk PtNi intermetallic compound. At higher ratios of Ni/Pt, there is evidence for PINi and a separate phase is formed, which is probably Ni but cannot be distinguished from $\mathrm{Ni}_{3} \mathrm{P}_{1}(30)$ ). On L-zeolite, the coordination numbers do not conform to any simple model. 'The fact that $\mathrm{N}_{\mathrm{Pt}-\mathrm{Ni}}$ does not equal $\mathrm{N}_{\mathrm{Ni}-\mathrm{Pt}}$ (as it should for a $50 / 50$ composition by mass balance) indicates that there is a problem in the analysis, but whatever the problem here, there is little evidence for a true PiNi intermctallic phase in $\mathrm{L}$-zeolite as is found on the $\mathrm{SiO}_{2}$. Using the catalytic probe of cyclopropanc hydrogenation/hydrogenolysis (sec above), we can also rule out a separate Ni phase in the case of L-zeolite.

The XANES of the $\mathrm{SiO}_{2}$ supported bimctallic Pt-Ni catalysts suggest that there is electron transfer from Ni to Pt (7) which is the opposite to what would be predicted by bulk Pauling electronegativitics, but 
is consistent with the predictions of model system studies by surface science (25), i.c., one expects that Ni on the surface of the $\mathrm{Pt}$ particle will be less electron rich than pure $\mathrm{Ni}$. A simplistic interpretation of charge transfer between two metals would predict that the density of vacant states at the Fermi level would be decreased for the metal receiving charge (which would decrease the whiteline intensity of this metal) and the density of vacant states at the Fermi level would be increased for the metal donating the charge (which would increase the whiteline intensity of this metal). This is exactly the behavior observed as the Pl/Ni ratio is varied on the silica support with the $\mathrm{Pt}$ whitcline decreasing monotonically as the atomic fraction of $\mathrm{Ni}$ is increased and the Ni whiteline increasing as the atomic fraction of $\mathrm{Pt}$ is increased (7). As with the coordination numbers, the XANES of the L-zeolite supported Pt-Ni supported catalysts is more complex. The whitelines of $\mathrm{Ni}$ behave as on the $\mathrm{SiO}_{2}$ support, but the $\mathrm{Pt}$ whiteline increases in width slightly rather than decreasing monotonically in intensity with added $\mathrm{Ni}$ as in the case of $\mathrm{SiO}_{2}$. Whether this is the result of the very small pariicles, interactions with walls of the zeolite or both is not clear at this point.

While the stability of $\mathrm{Pt} / \mathrm{KL}$ toward self-poisoning during aromatization is high relative to $\mathrm{Pt}$ on other supports $(28,29)$, this is not the case with respect to deactivation by sulfur (31). In the presence of sulfur concentrations as low as $0.05 \mathrm{wt}$ ppm, the Pt agglomerates and moves out of the zeolite channels. We have used both X-ray absorption and transmission electron microscopy to investigate the possible increased stabilization of $\mathrm{Pt}$ against sulfur catalyzed agglomeration when promoted by Ni. Two samples, the Pt only and the highest Ni loaded catalysts were submitted to extended X-ray absorption fine structure (EXAFS) analysis. These results are reported in Table 6 below.

Table 6. EXAFS determined coordination number, $\mathrm{N}_{X-Y}$, interatomic distance, $\mathrm{R}_{\mathrm{X}-\mathrm{Y}}$, in $\AA$, and Debye Waller term, DWX-Y, in $\AA^{2}$ (where $X$ is the absorber and $Y$ the scatterer).

\begin{tabular}{|c|c|c|c|c|}
\hline EXAFS Parameters & $P \mathrm{P} / \mathrm{KL}$ & $\mathrm{S}, \mathrm{Pt} / \mathrm{KL}$ & $(0.44 \mathrm{Pt}-\mathrm{Ni} / \mathrm{KL}$ & $\mathrm{S}, 0.44 \mathrm{Pt}-\mathrm{Ni} / \mathrm{KL}$ \\
\hline$N_{p} p_{1} p_{1}$ & 7.1 & 9.0 & 3.8 & 3.6 \\
\hline $\mathrm{NPt}_{\mathrm{Pi}}$ & & & 1.6 & 1.8 \\
\hline $\mathrm{N}_{\mathrm{Ni}-\mathrm{Ni}}$ & & & 3.9 & 4.1 \\
\hline $\mathrm{NN}_{\mathrm{Ni}} \mathrm{P}_{1}$ & & & 1.4 & 1.8 \\
\hline$R_{P}^{\prime} ! P !$ & 2.77 & 2.77 & 2.72 & 2.72 \\
\hline$R_{P^{\prime}-N i}$ & & & 2.63 & 2.64 \\
\hline $\mathrm{R}_{\mathrm{Ni}-\mathrm{Ni}}$ & & & 2.54 & 2.54 \\
\hline$R_{\mathrm{Ni}-\mathrm{P}_{1}}$ & & & 2.6 .3 & 2.64 \\
\hline 1) $W_{1} P_{t} P_{1}$ & $(0.0(0)(0.5$ & $(0.0010$ & $0.0(0.32$ & $0.0(028$ \\
\hline DW $W_{\text {I't-Ni }}$ & & & $(0.0) 17$ & 0.0() 27 \\
\hline 1) $W_{\mathrm{Ni}-\mathrm{Ni}}$ & & & $0 .(0) 17$ & 0.0020 \\
\hline$D W_{N i-P I}$ & & & $-(0.0)(09$ & $0.0(036$ \\
\hline
\end{tabular}


The coordination number $N_{P t-P t}=7.1$ is consistent with a particle size of about $12 \AA$ for $P t / K L$ which grows to NPt-Pt $=9.0$ cquivalent to a particle sizc of about $20 \AA$. Thus, the EXAFS confirms that particle size increases with sulfiding. While a careful statistical particle size was not determined by transmission electron microscopy (TEM), most particles were in the range of 100-300 $\AA$ on the sulfided $\mathrm{Pt} / \mathrm{KL}$ catalyst and 10-30 $\AA$ on the three sulfided Pt-Ni/KL catalysts. Combining the EXAFS with the TEM, these results suggest a bimodel distribution of particles within the zeolite channels (mostly not seen in the TEM and of order $12 \AA$ ) and particles outside the zeolite and about $250 \AA$. From a simple volume average mass balance (assuming that the large particles outside the zeolite have a $\mathrm{NPt}_{\mathrm{Pt}} \mathrm{Pt}=12$ ), one finds that about $40 \%$ of the Pt has migrated outside the zeolite. Even though the particle size is larger following sulfiding (which usually implies more ordered particles), one should also note that the DWPt-Pt has increased indicating that sulfiding causes disorder as well as particle growth but note also that the $\mathrm{R}_{\mathbf{p t}-\mathrm{Pt}}$ is identical to that of bulk Pt, RPt-Pt $=2.77 \AA$.

Summarizing, we find a very large difference between $\mathrm{Pt}$ and $\mathrm{Ni}$ interaction when $\mathrm{SiO}_{2}$ and $\mathrm{L}$ zeolite supports are compared and these differenees are most obvious for Ni rich compositions. On $\mathrm{SiO}_{2}$, the dispersions are poor, the metal-metal interaction produces a PINi alloy (which can be identified by Xray diffraction) and excess $\mathrm{Ni}$ forms a separate $\mathrm{Ni}$ phase. In $\mathrm{L}$-zeolite, no separate Ni phase is formed at any composition investigated, but the clusters of $\mathrm{Pt}-\mathrm{Ni}$ do not appear to be a simple alloy structure either. The metal cluster dispersion is not much affected, perhaps because of the constraining influence of the $\mathrm{L}$ zeolite pore size, and the interaction of $\mathrm{Ni}$ with $\mathrm{Pt}$ has a positive effect on both inhibition of self-poisoning and sulfur catalyzed agglomeration of $\mathrm{Pt}-\mathrm{Ni} / \mathrm{KL}$-zeolite catalysts for $\mathrm{n}$-hexane reaction.

\section{REFERENCES}

1. D. E. Resasco, G. L. Haller, J. Calal. 82, 279 (1983).

2. Y.-J. Lin, D. E. Resasco, G. L. Haler, J. C. S. Faraday I 83, 2091 (1987).

3. G. L. Haller, D. E. Resasco, Adv. Catal. 36, 173 (1989).

4. M. McMillan, J. S. Brinen, J. D. Carruthers, G. L. Haller, Coll. Surf 38, 133 (1989).

5. C. Y. Lin, Ph. D., Yale University (1992).

6. G. Larsen, G. L. Haller, in Proc. 10th Intern. Congr. Catal. L. Gusczi, F. Solymosi, P. Télényi, Eds. (Elscvier Sci. Publ., Amsterdam, 1993), vol. Part A, pp. 297.

7. A. Jentys, B. J. McHugh, G. L. Haller, J. A. Lercher, J. Phys. Chem 96, 1324 (1992).

8. G. Iarsen, G. L. Haller, in Proc. Oth Intern. Zeolite Conf. R. v. Ballmoos, J. B. Higgins, M. M. J. Treacy, Eds. (Buttcrworth-Heinemann, Boston, 1993), vol. 2, pp. 441.

9. K. Tanabe, in Catalysis: Science and Technology J. R. Anderson, M. Boudart, Eds. (SpringerVerlag, Berlin, 1981), vol. 2, pp. 2.31. 
10. G. M. Kramer, G. B. McVicker, J. J. Ziemiak, J. Catal. 92, 355 (1985).

11. G. M. Kramer, G. B. McVicker, Acc. Chem. Res. 19, 78 (1986).

12. R. F. Mortlock, A. T. Bell, A. K. Chakraborty, C. J. Radke, J. Phys. Chem. 95, 4501 (1991).

13. J. Klinowski, Nature 346, 509 (1990).

14. J. A. Jones, P. J. Hore, J. Magn. Reson. 92, 276 (1991).

15. H. Barkhuijsen, R. deBecr, W. M. M. J. Bovéc, D. vanOrmondt, J. Magn. Reson. 61,465 (1985).

16. D. W. Sindorf, G. E. Maciel, J. Am. Chem. Soc. 102, 7606 (1980).

17. J. R. Bernard, in 5ti Intern. Conf. Zeolites(Heyden, London, 1980) pp. 686.

18. W. E. Alvarez, D. E. Resasco, Catal. Lett. 8, 53 (1991).

19. G. Larsen, G. L. Haller, Calal. Lett. 3, 103 (1989).

20. T. T. Phuong, J. Massardier, P. Gallezot, J. Catal. 102, 456 (1986).

21. C. Kittel, Elementary Solid State Physics (J. Wiley \& Sons, New york, 1962).

22. B. J. McHugh, G. Larsen, G. L. Haller, J. Phys. Chem. 94, 8621 (1990).

23. J. E. Benson, H. G. Wang, M. Boudart, J. Catal. 30, 146 (1973).

24. T. R. Hughes, W. C. Buss, P. W. Tamm, R. L. Jacobson, in New Developments in Zeolite Sci. and Tech. Y. M. c. al., Eds. (Kodansha-Elsevier, Tokyo, 1986) pp. 725.

25. J. A. Rodriguez, D. W. Goodman, J. Phys. Chem. 95, 4196 (1991).

26. J. A. Rodriguez, D. W. Goodman, J. Phys. Chem. 94, 5342 (1990).

27. J. Y. Lec, J. Schwank, J. Catal. 108, 495 (1987).

28. E. Iglesia, J. E. Baumgartner, in Proc. 9th Intern. Zeolite Conf. R. v. Ballmoos, J. B. Higgins, M. M. J. Treacy, Eds. (Butterworth-Heienemann, Boston, 1993), vol. 2,.

29. E. Iglesia, J. E. Baumgartner, in Proc. 10th Intern. Congr. Catal. L. Guczi, F. Solymosi, P. Tétényi, Eds. (Elscvier Sci. Pub., Amsterdam, 1993), vol. Part A,.

30. A. Jentys, G. L. Haller, J. A. Lercher, J. Phys. Chem. 97, 484 (1993).

31. G. B. McVicker, ct al., J. Catal. 139, 48 (1993). 
